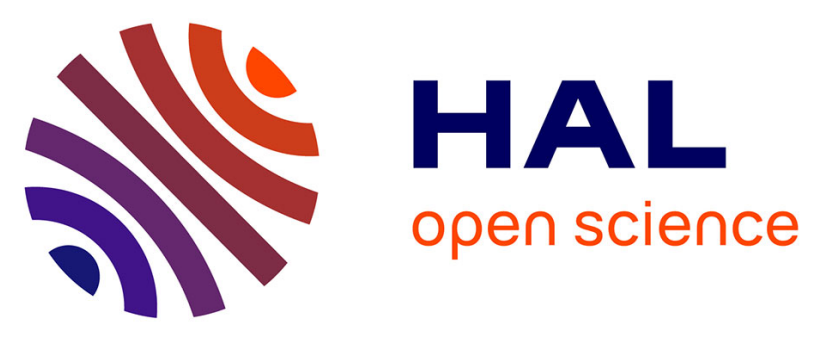

\title{
Asymmetric Solvent-Annealed Triblock Terpolymer Thick Films Topped by a Hexagonal Perforated Lamellar Nanostructure
}

Karim Aissou, Hana Bouzit, Felix Krusch, Jean-Pierre Mericq, Didier Cot, Nathalie Masquelez, Stéphanie Roualdes, Damien Quemener

\section{To cite this version:}

Karim Aissou, Hana Bouzit, Felix Krusch, Jean-Pierre Mericq, Didier Cot, et al.. Asymmetric SolventAnnealed Triblock Terpolymer Thick Films Topped by a Hexagonal Perforated Lamellar Nanostructure. Macromolecular Rapid Communications, 2022, 43, pp.2100585. 10.1002/marc.202100585 . hal03419294

\section{HAL Id: hal-03419294 \\ https://cnrs.hal.science/hal-03419294}

Submitted on 8 Nov 2021

HAL is a multi-disciplinary open access archive for the deposit and dissemination of scientific research documents, whether they are published or not. The documents may come from teaching and research institutions in France or abroad, or from public or private research centers.
L'archive ouverte pluridisciplinaire HAL, est destinée au dépôt et à la diffusion de documents scientifiques de niveau recherche, publiés ou non, émanant des établissements d'enseignement et de recherche français ou étrangers, des laboratoires publics ou privés. 


\title{
Asymmetric Solvent-Annealed Triblock Terpolymer Thick Films Topped by a Hexagonal Perforated Lamellar Nanostructure
}

\author{
Karim Aissou, ${ }^{1 *}$ Hana Bouzit, ${ }^{1}$ Felix Krusch,,${ }^{1}$ Jean Pierre Méricq, ${ }^{1}$ Didier Cot, ${ }^{1}$ Nathalie \\ Masquelez, ${ }^{1}$ Stéphanie Roualdes, ${ }^{1}$ and Damien Quémener ${ }^{1}$ \\ ${ }^{1}$ Institut Européen des Membranes, IEM, UMR 5635, Univ Montpellier, ENSCM, CNRS, \\ Montpellier, France
}

\section{E-mail: karim.aissou@umontpellier.fr}

\begin{abstract}
Asymmetric and nanostructured polystyrene-block-poly(2-vinyl pyridine)-blockpoly(ethylene oxide) (PS- $b$-P2VP- $b$-PEO or SVEO, S:V:EO $\approx 56: 34: 10,79.5 \mathrm{~kg} \cdot \mathrm{mol}^{-1}$ ) thick films blended with $20 \mathrm{wt} \%$ of a short PS homopolymer (hPS, $10.5 \mathrm{~kg}^{\mathrm{mol}} \mathrm{m}^{-1}$ ) were achieved by combining the non-solvent induced phase separation (NIPS) process with a solvent vapor annealing (SVA) treatment. Here, the NIPS step allows for the formation of a highly-permeable sponge-like substructure topped by a dense thin layer exhibiting poorly-ordered nanopores while the subsequent SVA treatment enables to reconstruct the material top surface into a porous monolayer of well-ordered hexagonal perforated lamellae (HPL). This optimized film architecture generated by NIPS-SVA showed a mean water permeability of $860 \mathrm{~L} \mathrm{~h}^{-1} \mathrm{~m}^{-2} \mathrm{bar}^{-1}$, which is roughly twice time higher than the flux measured through NIPS made PS- $b-\mathrm{P} 2$ VP- $b-$ $\mathrm{PEO} / \mathrm{hPS}$ materials having poorly-ordered nanopores. The post-SVA treatment also revealed as a powerful tool to tailor the thickness of the nanostructure formed within the blended material since monoliths entirely composed of a HPL phase were produced by increasing the time of exposure to a chloroform stream. The water flux of such PS- $b$-P2VP- $b$-PEO/hPS monoliths was found to be an order of magnitude lower than that of their asymmetric film homologues.
\end{abstract}

Keywords: Solvent vapor annealing, block copolymer, self-assembly, asymmetric thick film, phase inversion process.

With their energy efficiency, manufacturing scalability, and ease of handling, ultrafiltration (UF) polymeric membranes are of particular interest in many applications such as protein separation and purification in the food and dairy industries, virus separation, and water treatment. ${ }^{1-4}$ However, conventional UF membranes innately bear a permeabilityselectivity trade-off, ${ }^{5}$ and are subject to fouling ${ }^{6}$ which is considered as one of the biggest challenges in separation technology. To overcome these issues, the development of novel 
strongly selective and high-flux performance UF membranes endowed with fouling-resistant uniform nanopores is urgently needed.

To make progress towards the manufacture of such advanced materials, an ideal membrane architecture design, comprising a macroporous substructure topped by a thin layer of densely packed fouling-resistant and monodisperse nanopores, needs to be implemented at large scale. For that purpose, amphiphilic block copolymer (BCP) chains are considered as excellent candidates due to their innate tendency to self-assemble over large scale into a high areal density of nearly uniform nanofeatures with tailorable size, shape and chemistry. ${ }^{7,8}$

Over the last decade, many efforts have been deployed to fabricate asymmetric and nanostructured $\mathrm{BCP}$ membranes devised with smart nanopores that can be potentially used to prevent the common problem of fouling. For instance, different external-stimuli responsive BCP membranes capable to adjust both the size and hydrophilic/hydrophobic character of their nanopores under changing environmental conditions (e.g., $\mathrm{pH}$ and temperature) have been manufactured by self-assembly and non-solvent induced phase separation (SNIPS), ${ }^{8-14}$ which should allow facilitating the removal of foulants. ${ }^{15}$ To extend this concept, the nanodesign of smart BCP membranes having double-stimuli responsive pores has also been demonstrated. ${ }^{16,17}$

Besides, as one of the most efficient methods to manufacture antifouling membrane is to weaken the interactions between the foulants and materials, the use of a hydrophilic block having a strong water affinity and large excluded volume is envisioned as a promising alternative to build fouling-resistant nanopores. ${ }^{18}$ In this direction, poly(ethylene oxide) (PEO)containing $\mathrm{AB}$ - and $\mathrm{ABC}$-type $\mathrm{BCPs}$ have been used to achieve asymmetric and nanostructured membranes with possibly improved fouling resistance and biocompatibility since PEO is wellknown for its superior antifouling and low toxicity properties. ${ }^{19-21}$

In this work, we efficiently combine the non-solvent induced phase separation (NIPS) process and a solvent vapor annealing (SVA) treatment to produce PEO-containing ABC 
triblock terpolymer thick films comprising a sponge-like substructure and a complex nanostructured top surface layer which differs from the common cylindrical phase generated by SNIPS. Indeed, we show that the disordered phase generated by NIPS on the top surface of blended polystyrene- $b$-poly(2-vinyl pyridine)- $b$-PEO (PS- $b$-P2VP- $b$-PEO) thick films is transformed into a monolayer of well-ordered hexagonal perforated lamellae (HPL) when exposed to a chloroform vapor for $45 \mathrm{~min}$. This optimized material architecture with PEO-based nanochannels surrounded by a pH-responsive P2VP corona showed a water permeability value as high as $860 \mathrm{~L} \mathrm{~h}^{-1} \mathrm{~m}^{-2}$ bar $^{-1}$. Solvent-annealed $\left(5 \mathrm{~h}, \mathrm{CHCl}_{3}\right)$ monoliths entirely composed of the HPL structure were also demonstrated. As the nanochannel tortuosity increases with the thickness of the HPL phase, blended PS- $b$-P2VP- $b$-PEO monoliths showed a lower water permeability $\left(30 \mathrm{~L} \mathrm{~h}^{-1} \mathrm{~m}^{-2} \mathrm{bar}^{-1}\right)$.

\section{Results}

Figure 1a shows a typical square shaped (side $a=3 \mathrm{~cm}$ ) PS- $b$-P2VP- $b$-PEO thick film blended with 20 wt. $\%$ of hPS $\left(10.5 \mathrm{~kg} \cdot \mathrm{mol}^{-1}\right)$ that was manufactured by NIPS from a $18 \mathrm{wt} . \%$ polymer solution in a di-solvent mixture of 1,4-dioxane and tetrahydrofuran (DOX/THF: 80/20 by weight). Importantly, the terpolymer thick films have been blended with small hPS chains to prevent the formation of cracks when the material is immersed in the water bath. This blended terpolymer thick film with a uniform dry thickness of $\sim 36 \mu \mathrm{m}$ was produced by casting the polymer solution on a silicon substrate using a doctor blade with $250 \mu \mathrm{m}$ gap, then by allowing the solvent to partially evaporate prior to plunge the film into a deionized water bath. As shown here, the resulted polymeric film dried at ambient conditions was deposited on a porous hydrophilic polyvinylidene difluoride (PVDF) support before its use in water flux tests (see the results discussed hereafter). The scanning electron microscopy (SEM) image presented in Figure 1b shows the representative top surface and substructure morphologies of a blended PS- 
$b$-P2VP- $b$-PEO thick film generated by NIPS for a solvent evaporation time of 60 s. In such conditions, the asymmetric thick film consists of a macroporous substructure morphology topped by a "dense" and nanoporous skin layer. It is noteworthy that an integral asymmetric thick film is generated by NIPS. Indeed, the bottom film layer, in contact with the silicon support before to be plunged in the water bath, mainly consists of an open network structure and big holes with no-evidence of preferential interactions of the PEO and P2VP domains with the silicon top surface (see Fig. S1). Both the magnified topographic atomic force microscopy (AFM) and SEM top view images presented in Figures 1c-d indicate that the pores generated on the material top surface form a poorly-ordered phase with a mean center-to-center spacing of $\sim 43 \mathrm{~nm}$, extracted from their respective fast transform Fourier (FFT) images. Note that the mean diameter size of the P2VP/PEO domains of $\sim 19.1 \mathrm{~nm}$ (standard deviation, $\mathrm{SD}=5.7 \mathrm{~nm}$ ) does not correspond to the effective pore diameter since the P2VP- $b$-PEO chains partially fill their domains. Intriguingly, a well-ordered hexagonal array of P2VP/PEO features with a period of $\sim 32.5 \mathrm{~nm}$ and mean domain diameter size of $\sim 16.5 \mathrm{~nm}(\mathrm{SD}=2.3 \mathrm{~nm})$ is randomly observed in the corner regions of the blended PS- $b$-P2VP- $b$-PEO thick films but this long-range ordered phase was not properly stabilized in this study (see Fig. S2). Such results are in accordance with previous studies demonstrating that the preparation of asymmetric and isoporous PS- $b$-P2VP$b$-PEO thick films by SNIPS requires extensive optimization, due to the complex interplay of influencing parameters, such as solvent composition, polymer molecular weights, casting solution concentration and evaporation time. ${ }^{22}$ 

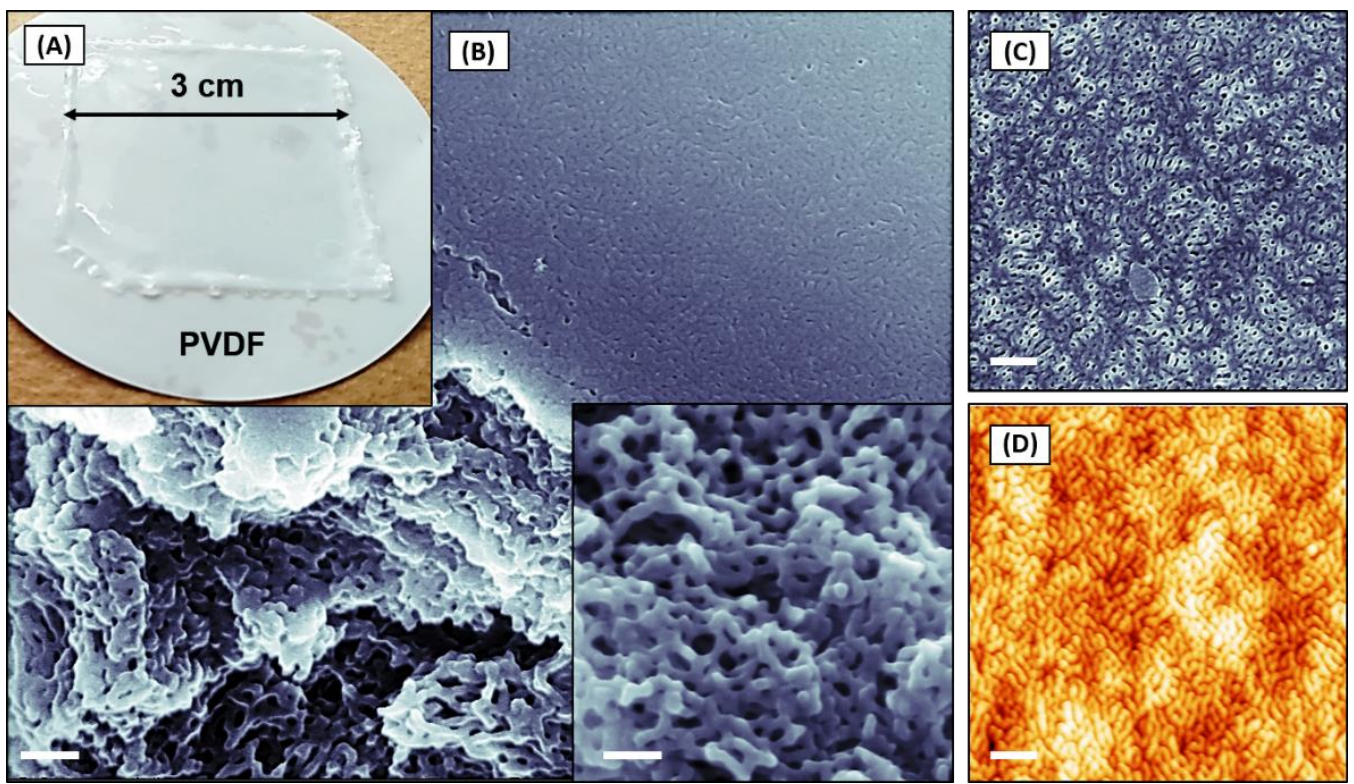

Figure 1: (a) Square shaped PS- $b$-P2VP- $b$-PEO/hPS thick film $(\sim 36 \mu \mathrm{m})$ generated by NIPS then deposited on a porous hydrophilic PVDF support. (b) Top view SEM image of a NIPSmade PS- $b$-P2VP- $b$-PEO/hPS thick film revealing that the material architecture consists of a macroporous substructure topped by a dense and nanoporous skin layer. (c) and (d) Magnified top view SEM and AFM topographic images showing that the material top surface generated by NIPS exhibits poorly-ordered nanopores. Samples were treated by a CF4 plasma prior both AFM and SEM imaging to enhance the contrast between PS and P2VP/PEO domains. Inset: Magnified SEM image showing that the macroporous substructure generated by NIPS adopts an open network structure. Scale bars: $250 \mathrm{~nm}$.

To facilitate this optimization, Nunes and cowokers have recently proposed a semiempirical method based on a guiding trend line calculated from the segregation strength analysis of the polymer-solvent mixtures supported by TEM imaging micelles in dilute solutions. ${ }^{23}$ Here, we efficiently combine the NIPS process and the SVA approach (referred as NIPS-SVA) ${ }^{24}$ to demonstrate that asymmetric thick films can also be manufactured with a very well nanostructured top surface derived from the self-assembly of PS- $b$-P2VP- $b$-PEO chains at equilibrium. Figure 2 shows an asymmetric PS- $b$-P2VP- $b$-PEO/hPS thick film generated by NIPS-SVA then etched by a $\mathrm{CF}_{4}$ plasma to enhance both SEM and AFM image contrasts. A well-ordered nanostructure is produced on the material top surface when the polymeric film is exposed to a $\mathrm{CHCl}_{3}$ vapor during $45 \mathrm{~min}$. 


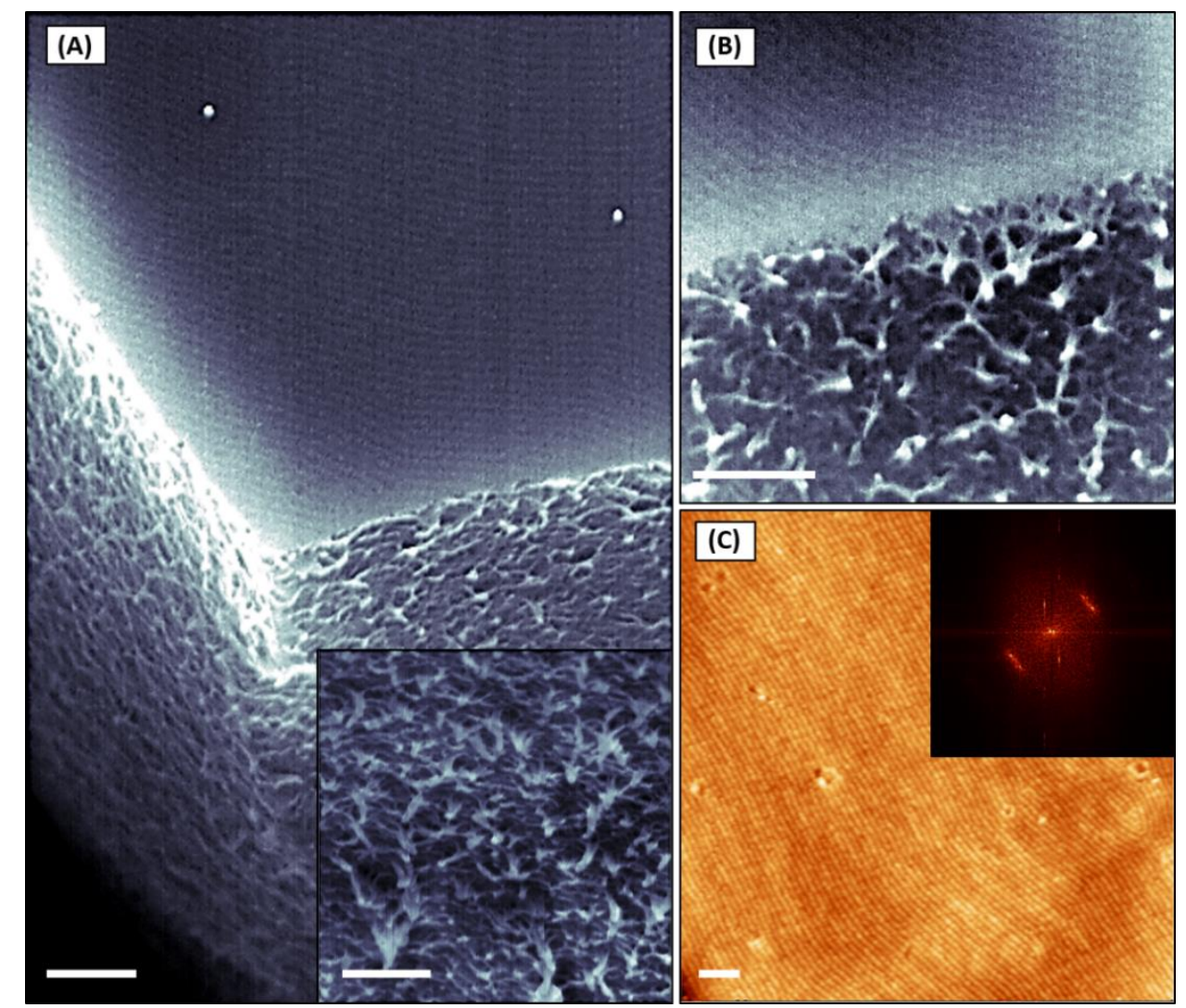

Figure 2: (a) and (b) Top view SEM images of a PS- $b$-P2VP- $b$-PEO/hPS thick film generated by NIPS then exposed to a $\mathrm{CHCl}_{3}$ vapor for $45 \mathrm{~min}$. Here, the solvent-annealed PS- $b-\mathrm{P} 2 \mathrm{VP}-b-$ PEO/hPS thick film $(\sim 9 \mu \mathrm{m})$ consists of a sponge-like substrate topped by a monolayer of OP lamellae. (c) AFM topographic image of a NIPS-SVA made (45 min, $\mathrm{CHCl}_{3}$ ) PS- $b$-P2VP- $b-$ $\mathrm{PEO} / \mathrm{hPS}$ thick film revealing that a long-range-ordered lamellar nanostructure with a period of $\sim 38 \mathrm{~nm}$, as extracted from the 2D-FFT, is produced on the material top surface. Samples were treated by a CF4 plasma prior both AFM and SEM imaging to enhance the contrast between PS and P2VP/PEO domains. Inset: Magnified SEM image showing that the macroporous gutter layer generated by NIPS is transformed into a microporous (sponge-like) substructure after the SVA treatment. Scale bars: $250 \mathrm{~nm}$.

The cross-sectional SEM views presented in Figures 2a-b show that the blended PS- $b$-P2VP$b$-PEO thick film consists of a sponge-like substructure topped by an out-of-plane (OP) lamellar thin layer (sub-50 nm thick). Note that the formation of a denser sponge-like substructure during the SVA treatment makes that the thickness of the blended PS- $b$-P2VP- $b$-PEO film $(\sim 9 \mu \mathrm{m})$ is now 4 times lower than that of the as-cast (no SVA) material. The 2D-FFT of the AFM topographic image displayed in Figure 2c indicates that the well-ordered top structure, consisting of an alternation of PS (bright) and P2VP/PEO (dark) lamellae, has a period of $\sim 38$ $\mathrm{nm}$. Although this pattern is the most frequently observed on the material-air interface, the 
presence of another crystallographic plane oriented parallel to air surface indicates that the nanostructure is rather a hexagonal perforated lamellar phase. Indeed, the AFM topographic images presented in Figure 3 show projections normal to the perforated layers where the PS lamellae and perforations appear bright while P2VP/PEO lamellae are dark after treating the terpolymer film with a $\mathrm{CF}_{4}$ plasma.

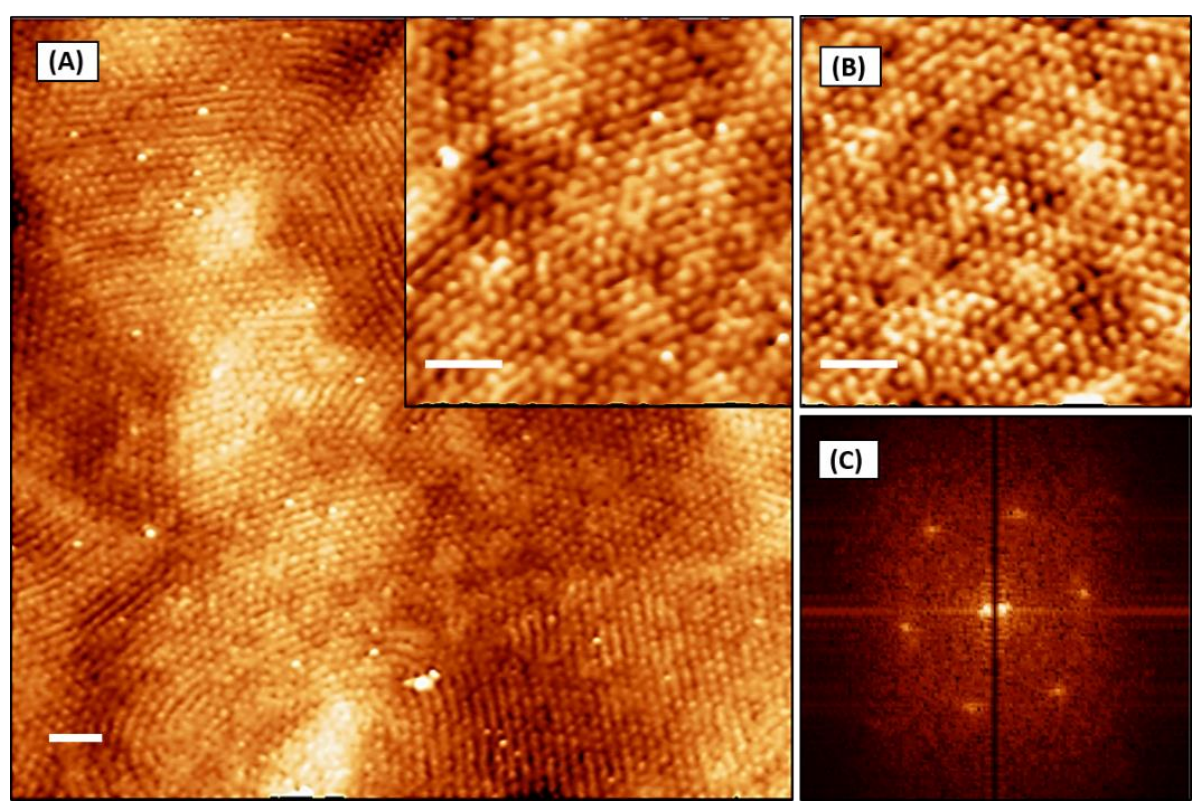

Figure 3: (a) AFM topographic image of a NIPS-SVA made (45 min, $\mathrm{CHCl}_{3}$ ) PS- $b$-P2VP- $b$ $\mathrm{PEO} / \mathrm{hPS}$ thick film treated by $\mathrm{CF}_{4}$ plasma showing a hierarchical fingerprint pattern on the material top surface, composed of an alternation of PS (bright) and P2VP/PEO (dark) lamellae with PS bright perforations enclosed in the P2VP/PEO lamellae. (b) AFM topographic image and (c) its 2D-FFT revealing that the PS perforations formed within the P2VP/PEO lamellae are locally arranged into a hexagonal array with a period of $\sim 38 \mathrm{~nm}$. Inset: Magnified AFM topographic image of the PS- $b$-P2VP- $b$-PEO/hPS thick film top surface clearly showing the presence of bright dots arising from the PS perforations. Scale bars: $200 \mathrm{~nm}$.

A "fingerprint pattern" formed by a lamellar structure, including some bright dots arising from PS perforations, can be observed from the Figure 3a while the AFM topographic view and its associated 2D-FFT displayed in Figures 3b-c indicate theses perforations are locally arranged into a hexagonal array with a period of $\sim 38 \mathrm{~nm}$, in accordance with a HPL structure. Note that well-ordered PS perforations extended through P2VP/PEO lamellae are also observed on the material free surface along a crystallographic plane belonging to the $\{110\}$ family, thereby confirming a high crystalline quality of the HPL structure formed on the sponge-like 
substructure (see Fig. S3). To evidence that a nanophase-separation between the P2VP and PEO blocks should take place within the perforated-lamellar structure, differential scanning calorimetry (DSC) measurements were performed on the PS- $b$-P2VP- $b$-PEO powder (see Fig. S4). In addition to the superposition of the PS and P2VP glass transition temperatures occurring at $\sim 89^{\circ} \mathrm{C}$, the heat flow curve reveals the melting point of $\mathrm{PEO}\left(T_{\mathrm{m}} \approx 49^{\circ} \mathrm{C}\right)$, which supports the P2VP and PEO blocks are nanophase-separated from each other as expected for triblock terpolymer chains having a linear topology. The formation of a tricolored pattern produced from self-assembled PS- $b$-P2VP- $b$-PEO chains was also reported by Huang $e t a l .^{25}$

To highlight the formation of a periodic and interconnected network morphology within the PS- $b$-P2VP- $b$-PEO/hPS thick films, the number of layers (i.e., thickness) of the HPL structure has been increased by exposing the polymeric materials to a $\mathrm{CHCl}_{3}$ vapor for longer time durations. The top view SEM image presented in Figure 4a shows that a $38 \mathrm{~nm}$ period fingerprint lamellar pattern is also produced at the material-air interface when the blended terpolymer thick film is placed under a $\mathrm{CHCl}_{3}$ stream during $5 \mathrm{~h}$. In addition, the cross-sectional view SEM image of the full $9 \mu \mathrm{m}$ thick PS- $b$-P2VP- $b$-PEO/hPS film reveals that the material is homogenously dense across the whole film thickness (see Fig. 4b). Representative SEM images of the upper, middle and lower regions of a solvent-annealed $\left(5 \mathrm{~h}, \mathrm{CHCl}_{3}\right) \mathrm{PS}-b$-P2 VP$b$-PEO/hPS layer confirm that the material asymmetry is not maintained when the SVA treatment is increased (see Fig. 4c-e). Indeed, a monolith entirely composed of the HPL structure is clearly evidenced by the presence of a periodic network phase extended from the air surface of the mesoporous material to the vicinity of the silicon substrate. It is noteworthy that the transformation of an asymmetric poly(1,1-dimethyl silacyclobutane)- $b$-PS- $b$-P2VP thick film, consisting of sponge-like substructure topped by a few hundred nanometer thick perforated lamellar (PL) structure, into an entirely PL-structured monolith has been recently 
reported in the literature by increasing the SVA treatment duration, but no flux performance results were provided. ${ }^{26}$

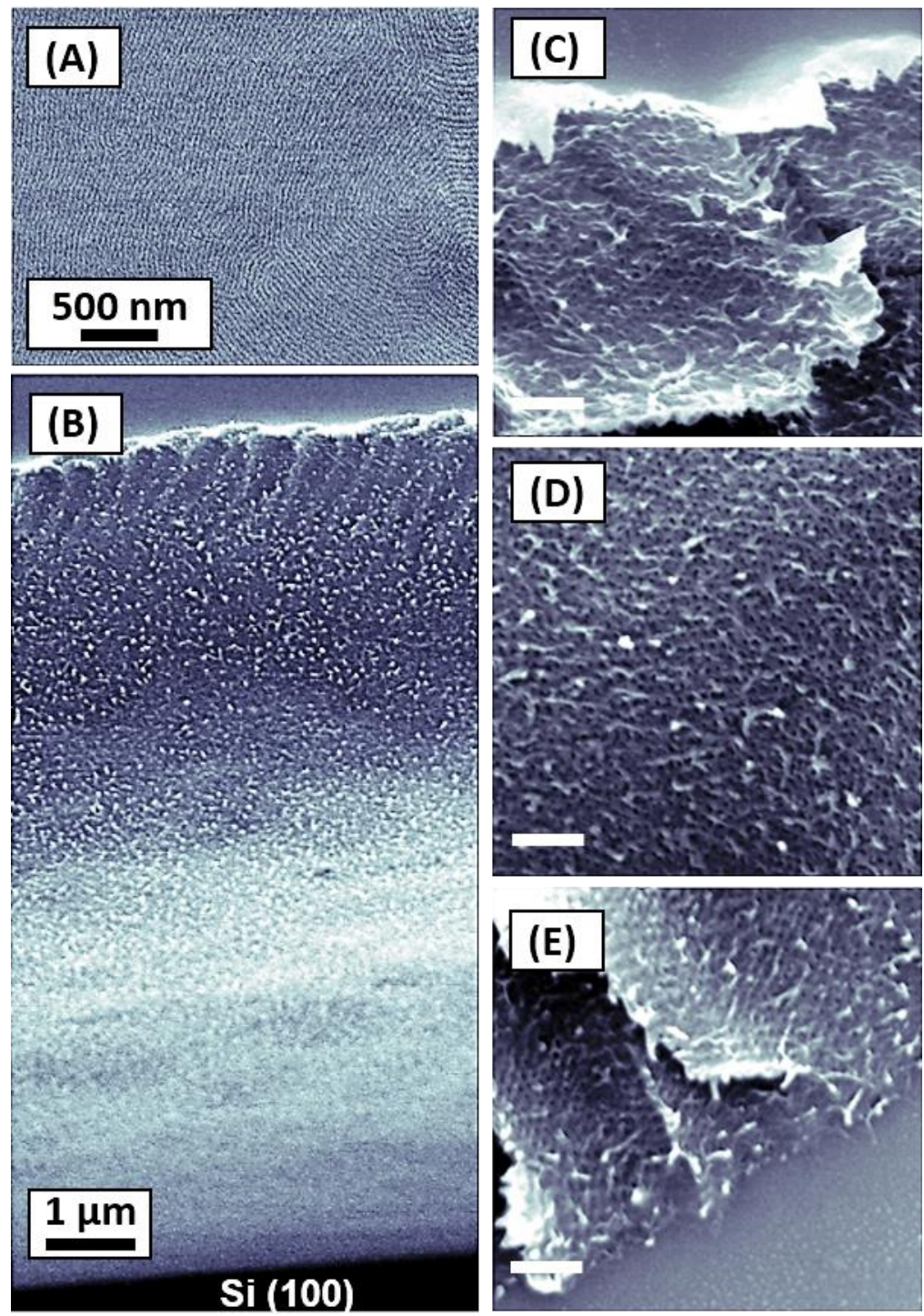

Figure 4: (a) Top view SEM image of a PS- $b$-P2VP- $b$-PEO/hPS thick film generated by NIPS then exposed to a $\mathrm{CHCl}_{3}$ vapor for $5 \mathrm{~h}$ from which a $38 \mathrm{~nm}$ period fingerprint lamellar pattern with a long-range order can be observed. Cross-sectional SEM views of a PS- $b$-P2VP- $b$ $\mathrm{PEO} / \mathrm{hPS}$ monolith generated by NIPS-SVA $\left(5 \mathrm{~h}, \mathrm{CHCl}_{3}\right)$ showing (b) the full material having a thickness of $\sim 9 \mu \mathrm{m}$ and the presence of a networked HPL nanostructure located (c) on the material air surface, (d) within the monolith and (e) in the vicinity of the Si substrate. Scale bars: $200 \mathrm{~nm}$.

Here, to study the effect of the asymmetric material-to-monolith transformation on the material flux performances, the water permeability of several PS- $b$-P2VP- $b$-PEO/hPS thick films exposed to a $\mathrm{CHCl}_{3}$ vapor during different times has been plotted as a function of water pressure applied from 0.5 to 1.5 bar, using a dead-end stirred ultrafiltration cell (see Fig. 5). 
Regardless of the SVA treatment duration, all PS- $b$-P2VP- $b$-PEO/hPS thick films deposited on a porous $(0.1 \mu \mathrm{m})$ hydrophilic PVDF support demonstrated an excellent stability over material failure at high feed pressure, as witnessed by a linear change in water flux with the increase in pressure drop.

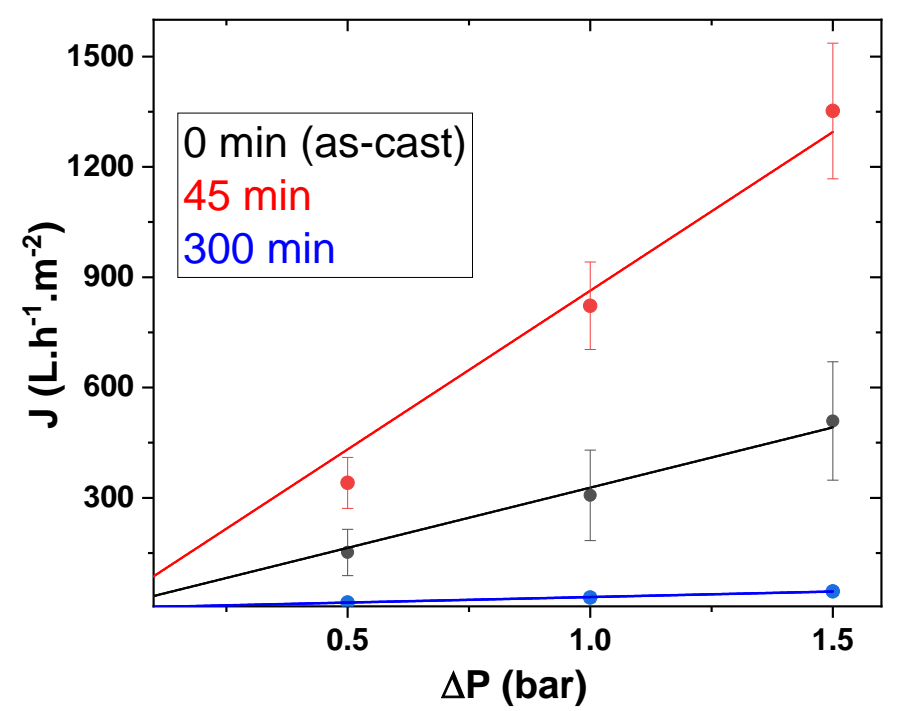

Figure 5: Water fluxes, $J$, of the NIPS made PS- $b$-P2VP- $b$-PEO/hPS materials exposed to a $\mathrm{CHCl}_{3}$ vapor for different times: (black dots) $0 \mathrm{~min}$, (red dots) $45 \mathrm{~min}$ and (blue dots) $300 \mathrm{~min}$. Error bars are the standard deviations of the mean relative permeability values calculated for 3 different samples.

The as-cast (no SVA) PS- $b$-P2VP- $b$-PEO/hPS thick film having a macroporous substructure showed a permeability of $330 \mathrm{~L} \mathrm{~h}^{-1} \mathrm{~m}^{-2}$ bar $^{-1}$ which is roughly 2.5 times smaller than the permeability through a solvent-annealed (45 min, $\left.\mathrm{CHCl}_{3}\right)$ HPL thick film having a (spongelike) microporous substructure $\left(860 \mathrm{~L} \mathrm{~h}^{-1} \mathrm{~m}^{-2} \mathrm{bar}^{-1}\right)$. To confirm that such an increase of the water transport is not dominated by the formation of macro defects (such as "cracks") within the PS- $b$-P2VP- $b$-PEO/hPS thick film during the SVA treatment, the rejection of $10 \mathrm{~nm}$ gold nanoparticles (NPs) is shown in the Figure S5. A rejection of $\sim 73 \%$ was achieved at 1 bar for the NIPS-SVA made (45 min, $\mathrm{CHCl}_{3}$ ) PS- $b$-P2 VP- $b$-PEO/hPS material suggesting that the water transport mainly occurs through the perforated-lamellar PEO-based nanodomains. Conversely, a colorless permeate with no absorption at $520 \mathrm{~nm}$ in the UV-visible spectrum can be achieved from as-cast PS- $b$-P2VP- $b$-PEO/hPS thick films, implying that the $10 \mathrm{~nm}$ gold NPs 
are completely blocked and, therefore, that the poorly ordered P2VP/PEO pores have their dimension below $10 \mathrm{~nm}$ (see Fig. S6).

The increase of the water transport through the solvent-annealed polymeric thick film is probably due mainly to the variation of the area occupied by the porous P2VP/PEO domains formed on the material skin layer since an OP lamellar morphology improves the $\mathrm{PS} /(\mathrm{P} 2 \mathrm{VP} / \mathrm{PEO})$ matrix/pore area ratio at the free surface in comparison with poorly-ordered nanofeatures, even if they are situated on top of a gutter layer with macropores. In other words, this behavior is in accordance with dimensionality reduction considerations implying that the water transport properties through cylinders are lower than that through lamellae. ${ }^{27}$ It is also noteworthy that the columnar-to-lamellar (rearrangement) transition occurring during the SVA treatment induces an increase of the PEO-based domain size that should be taken into account in the water permeability variation. This increase of the PEO-based domain size, evidenced by the gold NP retention tests, is also confirmed by the performance of bovine serum albumin (BSA) filtrations at $\mathrm{pH}$ of 7 (0.5 g/L of BSA in Milli-Q ultrapure water) since protein rejections of $\sim 69 \%$ and $\sim 4 \%$ were achieved at 1 bar from the NIPS and NIPS-SVA made (45 min, $\mathrm{CHCl}_{3}$ ) PS- $b$-P2VP- $b$-PEO/hPS thick films, respectively. For comparison, a rejection of $\sim 67 \%$ of BSA was demonstrated (at 0.5 bar and $\mathrm{pH}=7.4$ ) by the Peinemann group from asymmetric SNIPS-made PS- $b$-PEO membranes, consisting of a nanostructured top surface with wellordered OP PEO cylindrical domains and a macroporous substructure (water fluxes around 800$\left.850 \mathrm{~L} \mathrm{~h}^{-1} \mathrm{~m}^{-2} \mathrm{bar}^{-1}\right){ }^{28}$

By increasing the thickness of the HPL structure within the PS- $b$-P2VP- $b$-PEO/hPS thick films from few tens of nanometers to several micrometers, the water flux is drastically decreased. Indeed, by exposing the polymeric materials to a $\mathrm{CHCl}_{3}$ vapor during $2 \mathrm{~h}$, a thicker HPL-forming top layer is produced on the asymmetric PS- $b$-P2VP- $b$-PEO/hPS films, which conduces to a lower water permeability of $230 \mathrm{~L} \mathrm{~h}^{-1} \mathrm{~m}^{-2} \mathrm{bar}^{-1}$ (see Fig. S7). This phenomenon 
is more marked for the solvent-annealed $\left(5 \mathrm{~h}, \mathrm{CHCl}_{3}\right)$ HPL monoliths (see Fig. 4) since these symmetric films exhibit a water permeability of $30 \mathrm{~L} \mathrm{~h}^{-1} \mathrm{~m}^{-2} \mathrm{bar}^{-1}$, which is an order of magnitude lower compared to the maximized value achieved from asymmetric NIPS-SVA made (45min, $\mathrm{CHCl}_{3}$ ) PS- $b$-P2VP- $b$-PEO/hPS materials having a HPL monolayer (see Fig. 5). According the Hagen-Poiseuille law describing the relationship between the flux value and the tortuosity and thickness of the nanostructured layer, this result seems qualitatively consistent with a superior flux performance for the asymmetric PS- $b$-P2VP- $b$-PEO/hPS material having a lower porous nanochannel tortuosity due to the formation of a thinner HPL nanostructure.

\section{Conclusion}

Fouling-resistant PEO-containing terpolymer thick films with an advantageous architecture design, comprising a microporous substructure and a nanostructured porous top surface layer, has been achieved by using a simple and scalable methodology combining the conventional NIPS process with a SVA treatment used in advanced lithography application. By using this methodology, blended PS- $b$-P2VP- $b$-PEO thick films, showing a well-defined nanoporous perforated lamellar monolayer situated on top of a gutter layer, have been devised to provide an excellent water permeability value $\left(860 \mathrm{~L} \mathrm{~h}^{-1} \mathrm{~m}^{-2} \mathrm{bar}^{-1}\right)$. Such kind of asymmetric and nanostructured materials endowed with PEO-based porous nanochannels surrounded by a pH-responsive P2VP corona are highly desired to move towards the next-generation of strongly selective and high flux performance UF membranes having potential antifouling capabilities. However, as the perforated lamellar morphology generated by NIPS-SVA showed a lower protein rejection than that of the poorly ordered columnar phase manufactured by NIPS, we are currently working on the formation of a core-shell double gyroid structure with PEO-based nanochannels topping a sponge-like substructure in order to improve the selectivity of PS- $b$ P2VP- $b$-PEO made materials by reducing the pore dimensionality. 


\section{Methods}

Materials: Both the PS homopolymer $\left(10.5 \mathrm{~kg} \cdot \mathrm{mol}^{-1}\right)$ with a dispersity, $Ð$, of 1.09 and PS- $b$-P2VP- $b$-PEO terpolymer, consisted of PS $\left(\mathrm{S}=45 \mathrm{~kg} \cdot \mathrm{mol}^{-1}\right), \mathrm{P} 2 \mathrm{VP}\left(\mathrm{V}=26 \mathrm{~kg} \cdot \mathrm{mol}^{-1}\right)$ and PEO $\left(\mathrm{EO}=8.5 \mathrm{~kg} \cdot \mathrm{mol}^{-1}\right)($ volume fraction ratios, $\mathrm{S}: \mathrm{V}: \mathrm{EO}=56: 34: 10)$ and having $Ð$ of 1.05, were purchased from Polymer Source Inc., Canada. All the solvents: 1,4-dioxane (DOX, $>99 \%)$, tetrahydrofuran (THF, $>99 \%)$ and chloroform $\left(\mathrm{CHCl}_{3},>97 \%\right)$ were purchased from Sigma-Aldrich and used as received. $(0.1 \mu \mathrm{m}, 47 \mathrm{~mm})$ Hydrophilic Durapore PVDF supports (Merck Milipore) were purchased from Sigma-Aldrich and used as received.

Fabrication of asymmetric PS- $b$-P2VP-b-PEO/hPS thick films by NIPS: $36 \mu \mathrm{m}$ thick PS- $b$-P2VP- $b$-PEO thick films blended with 20 wt $\%$ of hPS were drawn onto $(3 \times 3 \mathrm{~cm})$ silicon substrates by using a simple tape casting technique with $250 \mu \mathrm{m}$ gap from a $18 \%$ wt. terpolymer solution in a di-solvent mixture (DOX/THF: $80 / 20$ by weight). To produce asymmetric terpolymer thick films, solvents were allowed to evaporate during 60s at room temperature (RT) to form a dense air surface layer with a kinetically trapped nanoporous structure, and then the blended PS- $b$-P2VP- $b$-PEO materials were immersed into a deionized water bath at RT for 5 min to produce a macroporous substructure. Importantly, in order to facilitate the peeling of the terpolymer thick films from their substrates, the silicon pieces were treated by an oxygen plasma in a home-made chamber (plasma conditions: $45 \mathrm{~W}, 75 \mathrm{mTorr} \mathrm{O}_{2}, 10 \mathrm{~min}$ ) prior to their use. Such a plasma treatment makes that the blended PS- $b$-P2VP- $b$-PEO thick films are detached from their substrate after several minutes spent in the water bath.

Fabrication of nanostructured asymmetric films and monoliths by SVA: Prior to placing the blended PS- $b$-P2VP- $b$-PEO material in the SVA chamber, the polymeric film floating in the non-solvent bath were deposited on a PVDF support, and the excess of water (mainly visible droplets) has been removed by absorbing the liquid with a Kimtech wipe. The self-assembly of PS- $b$-P2VP- $b$-PEO terpolymers was promoted by exposing films for different 
times (ranging from $0 \mathrm{~h}$ to $5 \mathrm{~h}$ ) to a continuous stream of $\mathrm{CHCl}_{3}$ vapor produced by bubbling nitrogen gas through the liquid solvent as described previously. ${ }^{29}$ This continuous flow system was used to control the $\mathrm{CHCl}_{3}$ vapor pressure in the chamber by dilution with a separate $\mathrm{N}_{2}$ stream so that a solvent vapor consisted of $32 \mathrm{sccm} \mathrm{CHCl}_{3}$ vapor and $8 \mathrm{sccm} \mathrm{N}_{2}$ (total $40 \mathrm{sccm}$ ). Importantly, the HPL structure produced on the dense top layer during the early stage of the SVA treatment grows at the expense of the sponge-like substructure until the formation of a monolith entirely composed of the network structure.

SEM, AFM and DSC characterizations: Scanning electron microscopy (SEM, Hitachi S-4800) was used at an accelerating voltage of $5 \mathrm{kV}$ to acquire images of both asymmetric thick films and monoliths formed by a blend of PS- $b$-P2VP- $b$-PEO chains and a short PS homopolymer. Atomic force microscopy (AFM Nano-Observer, CSInstruments) was used in tapping mode to characterize the surface morphology of PS- $b$-P2VP- $b-\mathrm{PEO} / \mathrm{hPS}$ thick films. Silicon cantilevers (PPP-NCH, Nanosensors) with a typical tip radius of $\sim 5 \mathrm{~nm}$ were used. The resonance frequency of the cantilevers was about $235 \mathrm{kHz}$. Prior AFM and SEM imaging, blended PS- $b$-P2VP- $b$-PEO/hPS thick films were treated with a fluorine plasma in a homemade chamber to improve the AFM topographic image contrast (plasma conditions: $45 \mathrm{~W}, 75$ mTorr $\mathrm{CF}_{4}$, and 90s). The thermal study was conducted using a TAinstruments DSC Q20 calibrated with indium. A sample with a weight of $\sim 5 \mathrm{mg}$ was heated with a rate of $20^{\circ} \mathrm{C} \mathrm{min}{ }^{-1}$ to $370^{\circ} \mathrm{C}$ to promote the phase-separation of the PS- $b$-P2VP- $b$-PEO chains. This sample was then cooled to $-50^{\circ} \mathrm{C}$ with a rate of $20^{\circ} \mathrm{C} \mathrm{min}^{-1}$, followed by heating again prior to obtain the DSC endotherm.

Water flux performances, bovine serum albumin and $10 \mathrm{~nm}$ gold nanoparticle filtrations: The water permeability of the different PS- $b$-P2VP- $b-\mathrm{PEO} / \mathrm{hPS}$ thick films was measured in a $10 \mathrm{~mL}$ filtration cell (Amicon 8010 stirred cell) connected to a water reservoir and a compressed air line. The measurements were performed on $2.5 \mathrm{~cm}$ diameter PS- $b-\mathrm{P} 2 \mathrm{VP}-$ 
b-PEO/hPS material discs supported by a high permeable hydrophilic PVDF material (water permeability of $2960 \mathrm{~L} \mathrm{~h}^{-1} \mathrm{~m}^{-2} \mathrm{bar}^{-1}$, see Fig. S8) at pressures between 0 and 1.5 bar. The mass of water passing through the stacked materials (permeate) was recorded using a connected balance at regular time intervals for $10 \mathrm{~min}$. Water temperature was maintained at $20^{\circ} \mathrm{C}$ during the measurements while the error bars were calculated from 3 different samples (see Tables S1-3). Aqueous solutions containing monodisperse $10 \mathrm{~nm}$ gold NPs (Sigma-Aldrich, the commercial solution was diluted 15 times in Milli-Q ultrapure water) or BSA (Sigma-Aldrich, dispersed in Milli-Q ultrapure water to reach $0.5 \mathrm{~g} / \mathrm{L}$ at $\mathrm{pH}=7$ ) were used to evaluate the rejection of the NIPS and NIPS-SVA made (45 min, $\left.\mathrm{CHCl}_{3}\right)$ PS- $b$-P2VP- $b$-PEO/hPS thick films. Filtrations were performed at 1 bar with the filtration setup used to determine the water permeability. An UV-visible spectrometer (Shimadzu, UV-2401 PC) was used to measure the $10 \mathrm{~nm}$ gold NP concentrations in the feed, permeate and retentate solutions by recording its UV-visible spectrum over the 400-800 nm spectral range. The BSA concentrations of both permeate and retentate, were measured at $278 \mathrm{~nm}$ with the same UV-visible equipment.

\section{Acknowledgements}

This work was performed within the support of the ANR JCJC AFM_Ring project, grant ANR18-CE09-00xx of the French Agence Nationale de la Recherche and through the project TAKCLE/AXE-Membrane du Futur/09-2020 founded by the Institut Européen des Membranes (IEM).

\section{References}

(1) Abetz, V. Isoporous Block Copolymer Membranes. Macromol. Rapid Commun. 2015, 36 (1), 10-22. https://doi.org/10.1002/marc.201400556.

(2) Nunes, S. P. Block Copolymer Membranes for Aqueous Solution Applications. Macromolecules 2016, 49 (8), 2905-2916. https://doi.org/10.1021/acs.macromol.5b02579. 
(3) Park, H. B.; Kamcev, J.; Robeson, L. M.; Elimelech, M.; Freeman, B. D. Maximizing the Right Stuff: The Trade-off between Membrane Permeability and Selectivity. Science. 2017, pp 11381148. https://doi.org/10.1126/science.aab0530.

(4) Zhang, Y.; Sargent, J. L.; Boudouris, B. W.; Phillip, W. A. Nanoporous Membranes Generated from Self-Assembled Block Polymer Precursors: Quo Vadis? J. Appl. Polym. Sci. 2015, 132 (21), n/a-n/a. https://doi.org/10.1002/app.41683.

(5) Mehta, A.; Zydney, A. L. Permeability and Selectivity Analysis for Ultrafiltration Membranes. J. Memb. Sci. 2005, 249 (1-2), 245-249. https://doi.org/10.1016/J.MEMSCI.2004.09.040.

(6) Guo, W.; Ngo, H.-H.; Li, J. A mini-review on membrane fouling. Bioresour. Technol. 2012, 122, 27- 34 DOI: 10.1016/j.biortech.2012.04.089.

(7) Peinemann, K. V.; Abetz, V.; Simon, P. F. W. Asymmetric Superstructure Formed in a Block Copolymer via Phase Separation. Nat. Mater. 2007, 6 (12), 992-996. https://doi.org/10.1038/nmat2038.

(8) Phillip, W. A.; Mika Dorin, R.; Werner, J.; Hoek, E. M. V.; Wiesner, U.; Elimelech, M. Tuning Structure and Properties of Graded Triblock Terpolymer-Based Mesoporous and Hybrid Films. Nano Lett. 2011, 11 (7), 2892-2900. https://doi.org/10.1021/nl2013554.

(9) Nunes, S. P.; Behzad, A. R.; Hooghan, B.; Sougrat, R.; Karunakaran, M.; Pradeep, N.; Vainio, U.; Peinemann, K. V. Switchable PH-Responsive Polymeric Membranes Prepared via Block Copolymer Micelle Assembly. ACS Nano 2011, 5, 3516-3522, DOI: 10.1021/nn200484v.

(10) Gu, Y.; Wiesner, U. Tailoring Pore Size of Graded Mesoporous Block Copolymer Membranes: Moving from Ultrafiltration toward Nanofiltration. Macromolecules 2015, 48 (17), 6153-6159. https://doi.org/10.1021/acs.macromol.5b01296.

(11) Zhang, Z.; Simon, A.; Abetz, C.; Held, M.; Höhme, A.-L.; Schneider, E. S.; Segal-Peretz, T.; Abetz V. Hybrid Organic-Inorganic-Organic Isoporous Membranes with Tunable Pore Sizes and Functionalities for Molecular Separation. Adv. Mater. 2021, 2105251. https://doi.org/10.1002/adma.202105251.

(12) Qiu, X.; Yu, H.; Karunakaran, M.; Pradeep, N.; Nunes, S. P.; Peinemann, K. V. Selective Separation of Similarly Sized Proteins with Tunable Nanoporous Block Copolymer Membranes. ACS Nano 2013, 7 (1), 768-776. https://doi.org/10.1021/nn305073e.

(13) Nunes, S. P.; Sougrat, R.; Hooghan, B.; Anjum, D. H.; Behzad, A. R.; Zhao, L.; Pradeep, N.; Pinnau, I.; Vainio, U.; Peinemann, K.-V. Ultraporous Films with Uniform Nanochannels by Block Copolymer Micelles Assembly. Macromolecules 2010, 43 (19), 8079-8085. https://doi.org/10.1021/ma101531k.

(14) Mocan, M.; Wahdat, H.; van der Kooij, H. M.; de Vos, W. M.; Kamperman, M. Systematic 
variation of membrane casting parameters to control the structure of thermo-responsive isoporous membranes. J. Membr. Sci. 2018, 548, 502-509, DOI: 10.1016/j.memsci.2017.11.047.

(15) Ju, X.-J.; Liu, Z.; Chu, L.-Y.; Xie, R.; Wang, W. Stimuli-Responsive Smart Gating Membranes. Chem. Soc. Rev. 2015, 45 (3), 460-475. https://doi.org/10.1039/c5cs00692a.

(16) Clodt, J. I.; Filiz, V.; Rangou, S.; Buhr, K.; Abetz, C.; Höche, D.; Hahn, J.; Jung, A.; Abetz, V. Double Stimuli-Responsive Isoporous Membranes via Post-Modification of Ph-Sensitive SelfAssembled Diblock Copolymer Membranes. Adv. Funct. Mater. 2013, 23 (6), 731-738. https://doi.org/10.1002/adfm.201202015.

(17) Schacher, F.; Ulbricht, M.; Müller, A. H. E. Self-Supporting, Double Stimuli-Responsive Porous Membranes from Polystyrene-Block-poly(N,N-Dimethylaminoethyl Methacrylate) Diblock Copolymers. Adv. Funct. Mater. 2009, 19 (7), 1040-1045. https://doi.org/10.1002/adfm.200801457.

(18) Yang, H.; Wang, Z. G.; Lan, Q. Q.; Wang, Y. Antifouling ultrafiltration membranes by selective swelling of polystyrene/poly(ethylene oxide) block copolymers. J. Membr. Sci. 2017, 542, 226-232, DOI: 10.1016/j.memsci.2017.08.015

(19) Jung, A.; Filiz, V.; Rangou, S.; Buhr, K.; Merten, P.; Hahn, J.; Clodt, J.; Abetz, C.; Abetz, V. Formation of Integral Asymmetric Membranes of AB Diblock and ABC Triblock Copolymers by Phase Inversion. Macromol. Rapid Commun. 2013, 34 (7), 610-615. https://doi.org/10.1002/marc.201200770.

(20) Musteata, V.; Sutisna, B.; Polymeropoulos, G.; Avgeropoulos, A.; Meneau, F.; Peinemann, K.V.; Hadjichristidis, N.; Nunes, S. P. Self-assembly of polystyrene-b-poly(2-vinylpyridine)-bpoly(ethylene oxide) triblock terpolymers. Eur. Polym. J. 2018, 100, 121-131, DOI: 10.1016/j.eurpolymj.2017.10.016

(21) Hahn, J.; Filiz, V.; Rangou, S.; Clodt, J.; Jung, A.; Buhr, K.; Abetz, C.; Abetz, V. J. Structure formation of integral-asymmetric membranes of polystyrene-block-poly(ethylene oxide). Polym. Sci., Part B: Polym. Phys. 2013, 51 (4) 281- 290

(22) Marques, D. S.; Vainio, U.; Chaparro, N. M.; Calo, V. M.; Bezahd, A. R.; Pitera, J. W.; Peinemann, K.-V.; Nunes, S. P. Self-Assembly in Casting Solutions of Block Copolymer Membranes. Soft Matter 2013, 9 (23), 5557. https://doi.org/10.1039/c3sm27475f.

(23) Sutisna, B.; Polymeropoulos, G.; Musteata, V.; Peinemann, K.-V.; Avgeropoulos, A.; Smilgies, D.-M.; Hadjichristidis, N.; Nunes, S. P. Design of Block Copolymer Membranes Using Segregation Strength Trend Lines. Mol. Syst. Des. Eng. 2016, 1 (3), 278- 289, DOI: 10.1039/C6ME00033A 
(24) Aissou, K.; Mumtaz, M.; Demazy, N.; Pécastaings, G.; Fleury, G.; Hadziioannou, G. Periodic Bicontinuous Structures Formed on the Top Surface of Asymmetric Triblock Terpolymer Thick Films. ACS Macro Lett. 2019, 8, 923-930, DOI: 10.1021/acsmacrolett.9b00403

(25) Huang, H.; Zhong, B.; Zu, X.; Luo, H.; Lin, W.; Zhang, M.; Zhong, Y.; Yi, G. Fabrication of Ordered Nanopattern by Using ABC Triblock Copolymer with Salt in Toluene. Nanoscale Res. Lett. 2017, 12 (1), 491, DOI: 10.1186/s11671-017-2260-0

(26) Aissou, K.; Mumtaz, M.; Bouzit, H.; Pécastaings, G.; Portale, G.; Fleury, G.; Hadziioannou, G. Bicontinuous Network Nanostructure with Tunable Thickness Formed on Asymmetric Triblock Terpolymer Thick Films. Macromolecules 2019, 4413-4420, https://doi.org/10.1021/ acs.macromol.9b00572.

(27) Aryal, D.; Howard, M. P.; Samanta, R.; Antoine, S.; Segalman, R.; Truskett, T. M.; Ganesan, $\mathrm{V}$. Influence of pore morphology on the diffusion of water in triblock copolymer membranes. J. Chem. Phys. 2020, 152, 014904. https://doi.org/10.1063/1.5128119.

(28) Karunakaran M.; Nunes, S.P.; Qiu, X.Y.; Yu, H.Z.; Peinemann K.V. Isoporous PS-b-PEO ultrafiltration membranes via self-assembly and water-induced phase separation. J. Membr. Sci. 2014, 453, 471-477.

(29) Gotrik, K. W.; Hannon, A. F.; Son, J. G.; Keller, B.; Alexander-Katz, A.; Ross, C. A. Morphology Control in Block Copolymer Films Using Mixed Solvent Vapors. ACS Nano 2012, 6 (9), 8052-8059. https://doi.org/10.1021/nn302641z.

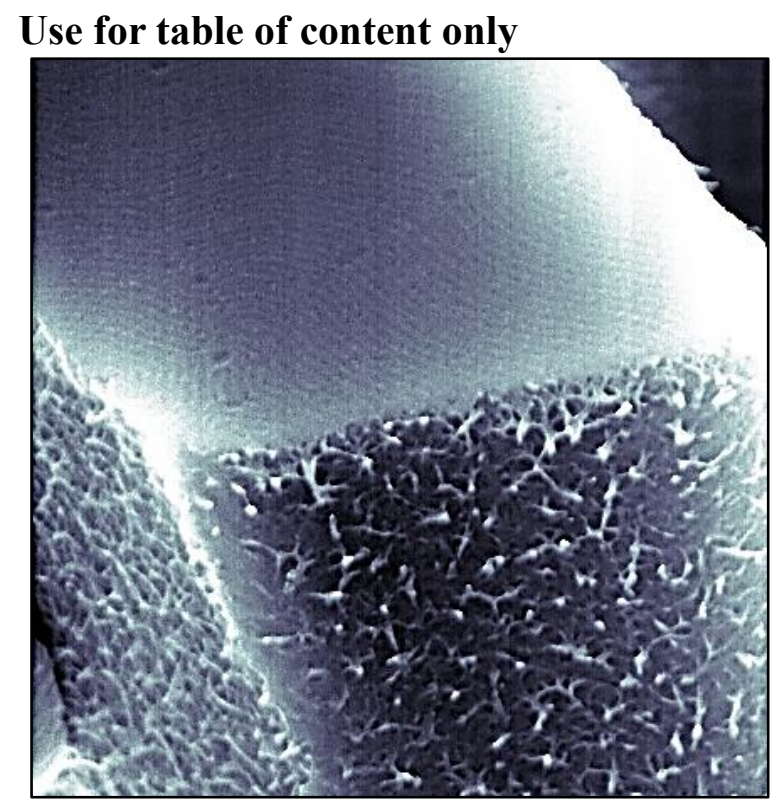




\title{
Supporting Information \\ Asymmetric Solvent-Annealed Triblock Terpolymer Thick Films Topped by a Hexagonal Perforated Lamellar Nanostructure
}

\author{
Karim Aissou, ${ }^{1 *}$ Hana Bouzit, ${ }^{1}$ Felix Krusch, ${ }^{1}$ Jean Pierre Méricq, ${ }^{1}$ Didier $\operatorname{Cot}^{1}$, Nathalie \\ Masquelez, ${ }^{1}$ Stéphanie Roualdes, ${ }^{1}$ and Damien Quémener ${ }^{1}$ \\ ${ }^{1}$ Institut Européen des Membranes, IEM, UMR 5635, Univ Montpellier, ENSCM, CNRS, \\ Montpellier, France
}

E-mail: karim.aissou@ umontpellier.fr
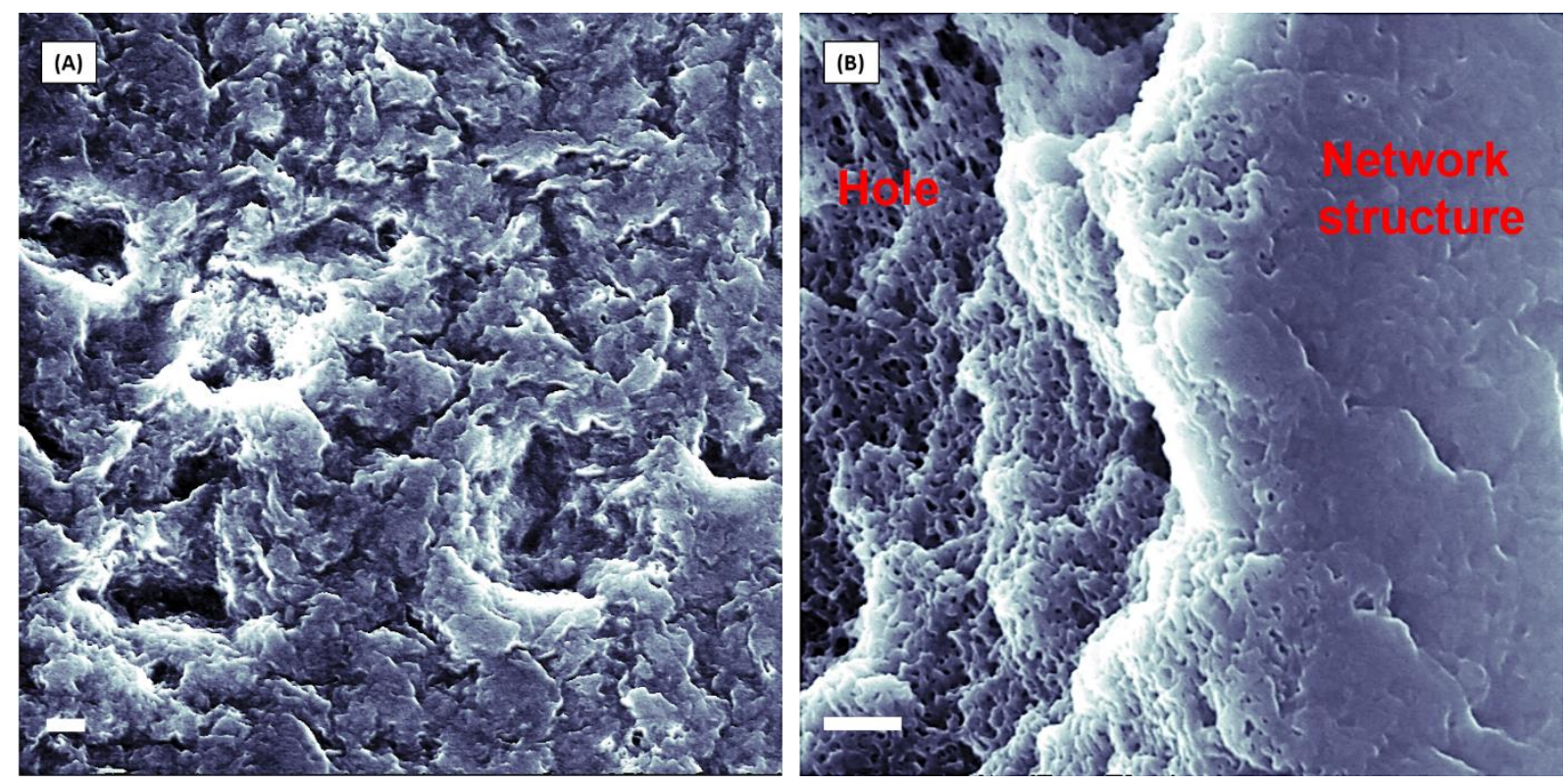

Figure S1: (a) $(10 \times 10 \mu \mathrm{m})$ and (b) $(5 \times 5 \mu \mathrm{m})$ top view SEM images taken from the bottom surface of a PS- $b$-P2VP- $b$-PEO/hPS thick film generated by NIPS. A rough bottom surface, consisting of big holes/cavities and an open network structure, can be observed with noevidence of preferential interactions of the PEO and P2VP domains with the silicon substrate. Scale bars: $500 \mathrm{~nm}$. 


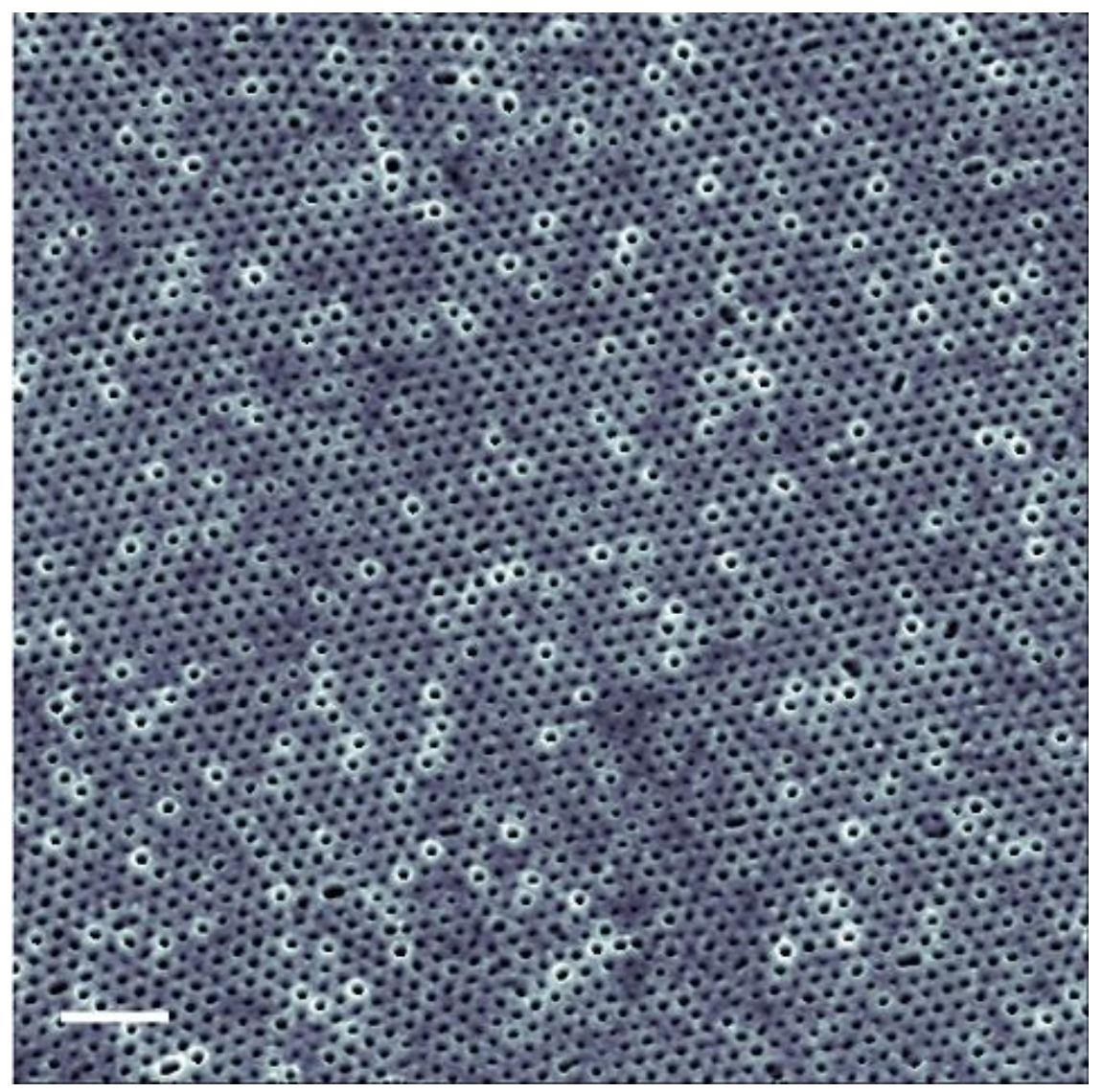

Figure S2: Top view SEM image taken from a corner region of the top surface of a PS- $b$-P2VP$b$-PEO/hPS thick film generated by NIPS, which shows PEO-based nanopores arranged into a well-ordered hexagonal array with a period of $\sim 32.5 \mathrm{~nm}$. Scale bar: $200 \mathrm{~nm}$.
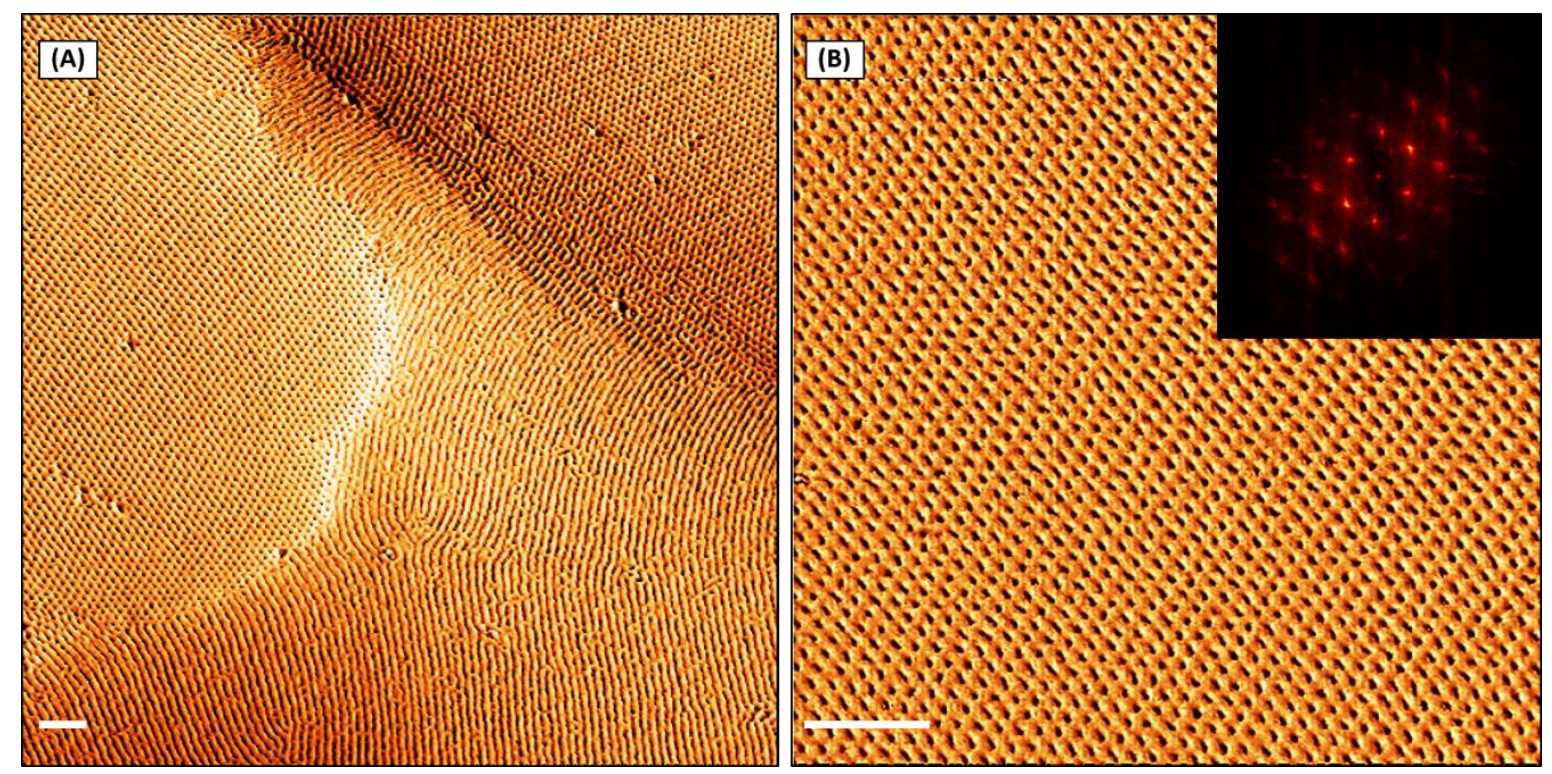

Figure S3: (a) $(4 \times 4 \mu \mathrm{m})$ and (b) $(1.5 \times 1.5 \mu \mathrm{m})$ AFM topographic views showing different plane orientations of the HPL nanostructure formed on the top surface of a solvent-annealed (45 min, $\mathrm{CHCl}_{3}$ ) PS- $b$-P2VP- $b$-PEO/hPS thick film. The 2D-FFT indicates that the PS (bright) perforations are arranged into a rhombic array with the lattice parameters $\mathrm{a}=38 \mathrm{~nm}$ and $\mathrm{b}=29$ nm along HPL (110) plane. Scale bars: $250 \mathrm{~nm}$. 


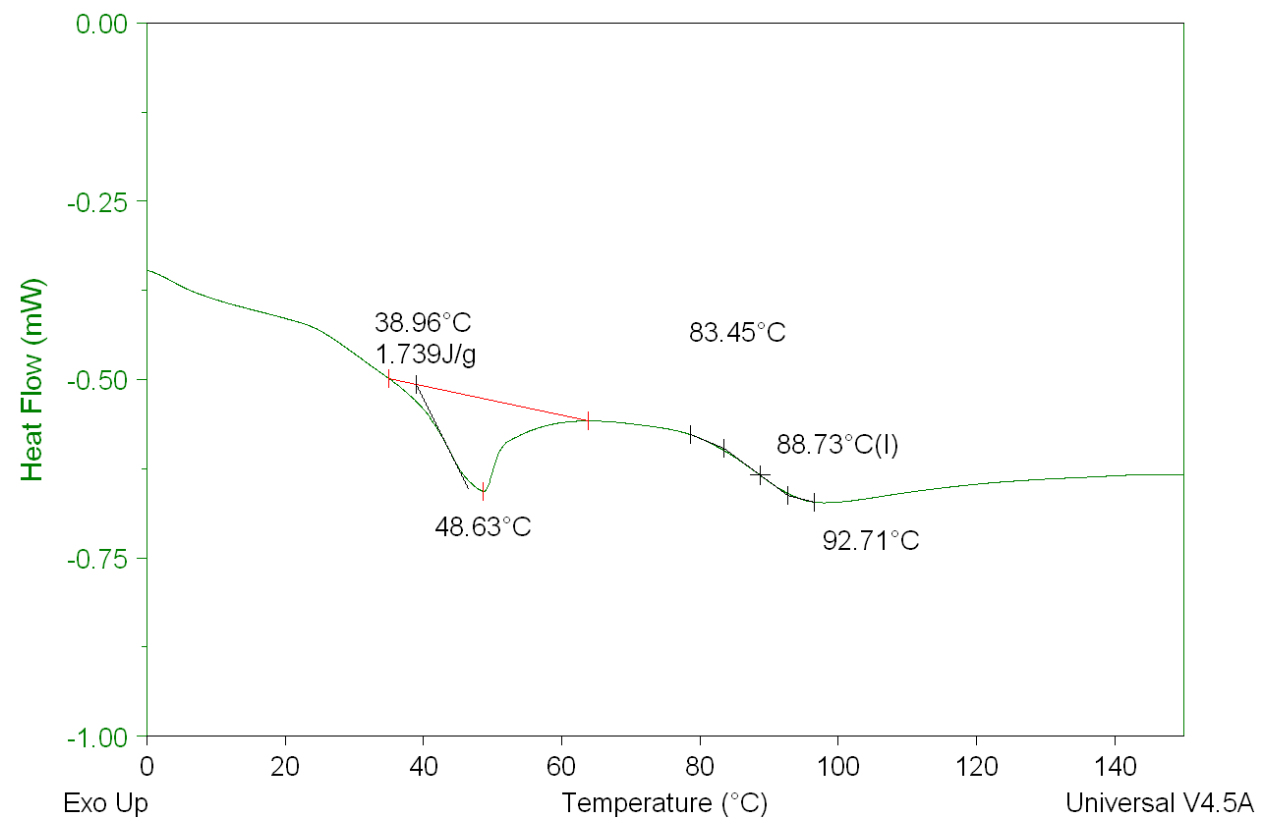

Figure S4: DSC trace of a PS- $b$-PS- $b$-PEO triblock terpolymer powder that was heated with a rate of $20^{\circ} \mathrm{C} \mathrm{min}^{-1}$ to $370^{\circ} \mathrm{C}$, followed by cooling to $-50^{\circ} \mathrm{C}$ with a rate of $20^{\circ} \mathrm{C} \mathrm{min}^{-1}$, and then by heating (rate of $20^{\circ} \mathrm{C} \mathrm{min}{ }^{-1}$ ) again to obtain the DSC endotherm.

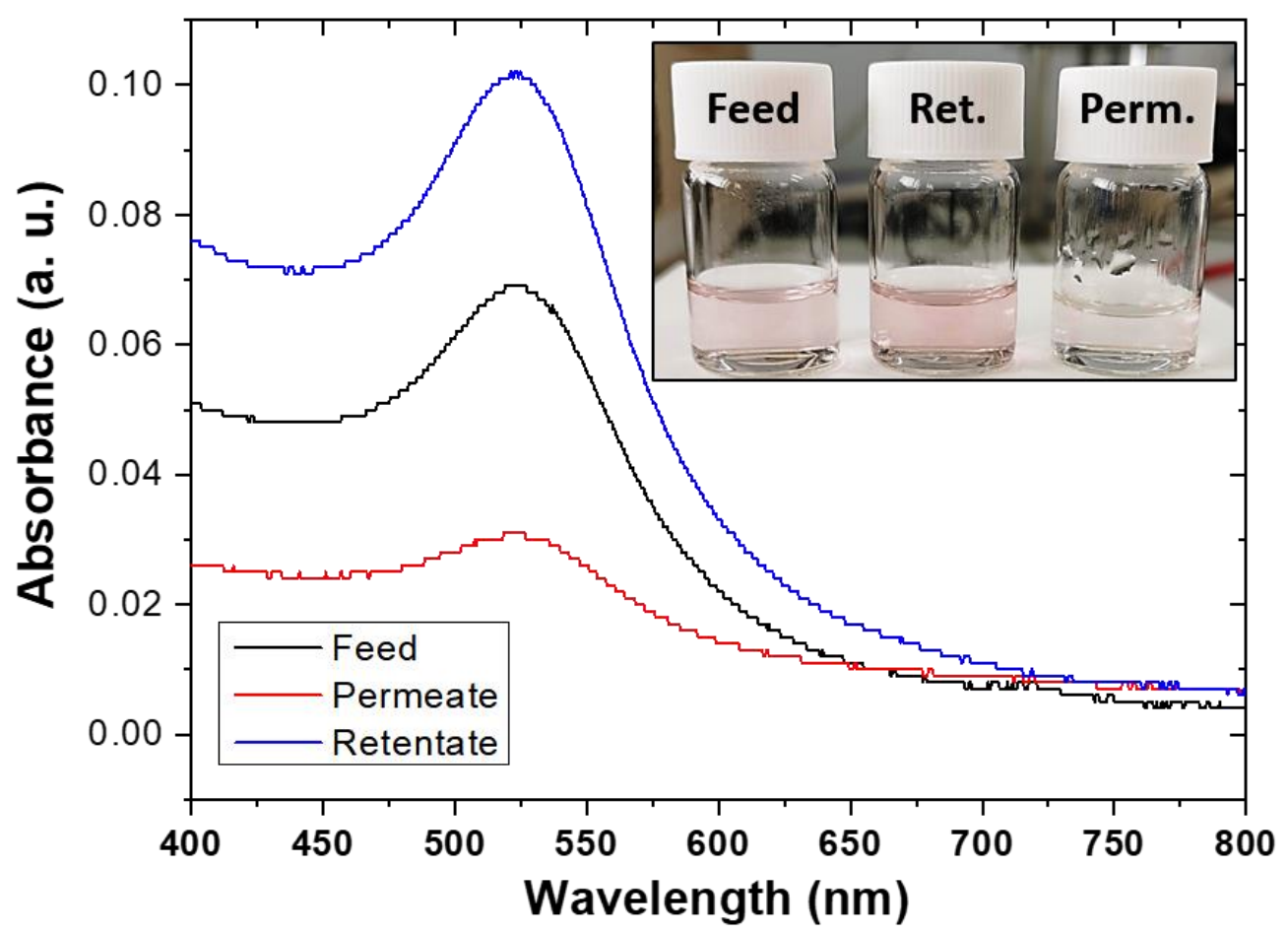

Figure S5: UV-visible spectra of the feed, retentate and permeate recorded over the 400-800 $\mathrm{nm}$ spectral range. All the UV-visible spectra mainly consists of a peak centered at approximately $520 \mathrm{~nm}$ that corresponds to the surface plasmon polariton generated by the 10 $\mathrm{nm}$ gold NPs. Inset: Photograph showing the colored (left) feed and (middle) retention solutions as well as the (right) nearly colorless permeate. 


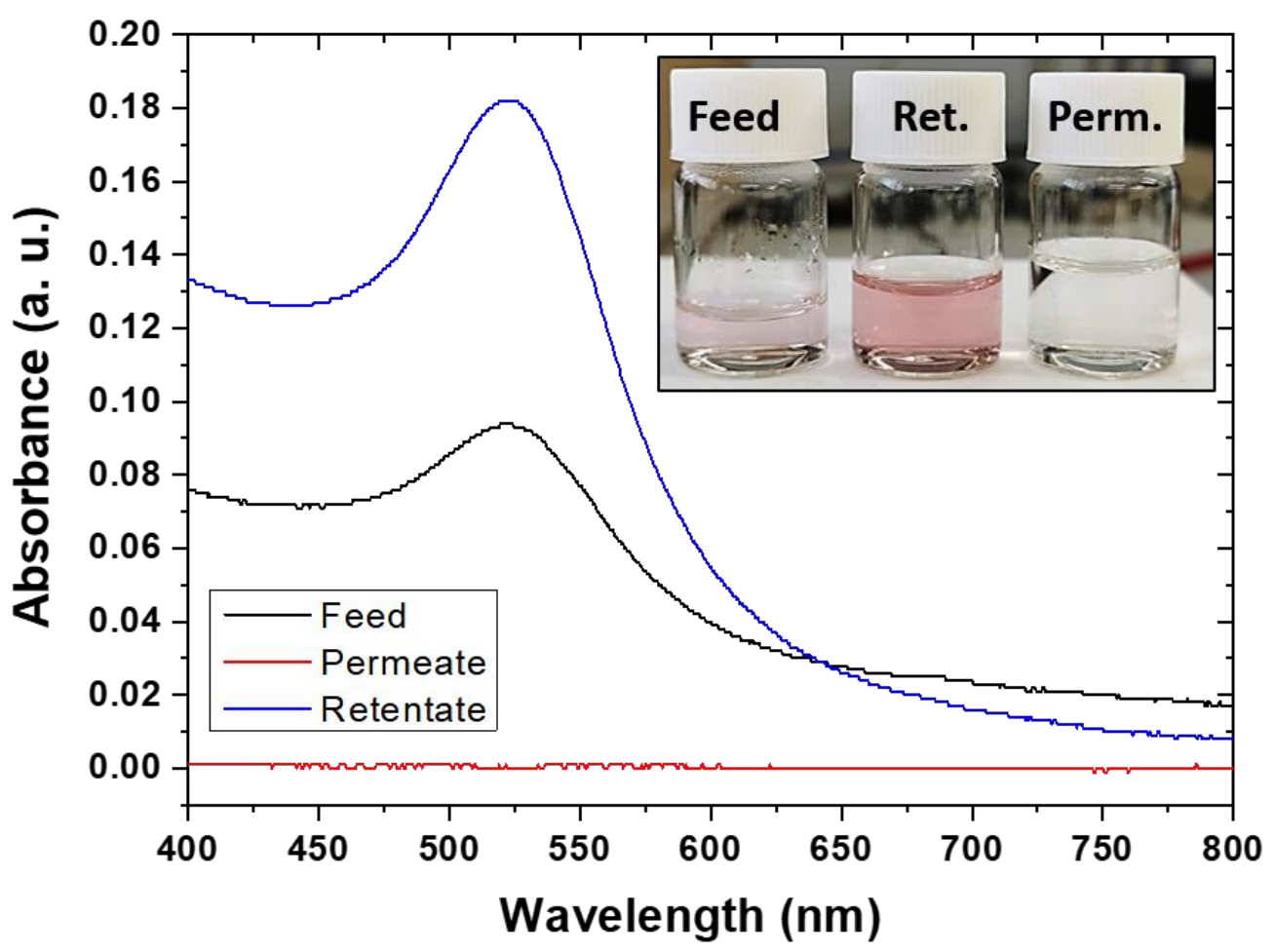

Figure S6: UV-visible spectra of the feed, retentate and permeate recorded over the 400-800 $\mathrm{nm}$ spectral range. The UV-visible spectra of the colored feed (black curve) and retention (blue curve) solutions mainly consists of a peak centered at approximately $520 \mathrm{~nm}$ that corresponds to the surface plasmon polariton generated by the $10 \mathrm{~nm}$ gold NPs. Conversely, no absorption peak is observed at $520 \mathrm{~nm}$ on the UV-visible spectrum (red curve) of the colorless permeate, which indicates an efficient rejection of the $10 \mathrm{~nm}$ gold NPs. Inset: Photograph showing the colored (left) feed and (middle) retention solutions as well as a (right) colorless permeate.

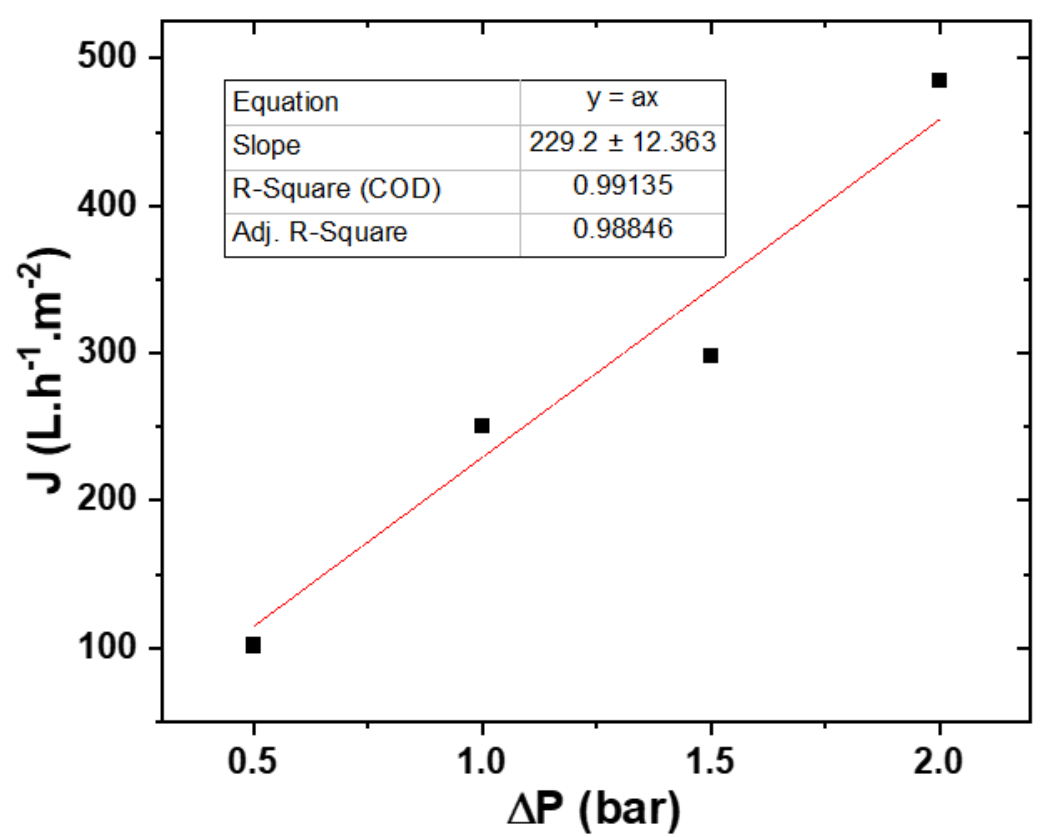

Figure S7: Water flux, $J$, of a solvent-annealed $\left(2 \mathrm{~h}, \mathrm{CHCl}_{3}\right)$ PS- $b$-P2VP- $b$-PEO/hPS thick film exhibiting a water permeability of $\sim 230 \mathrm{~L} \mathrm{~h}^{-1} \mathrm{~m}^{-2}$ bar $^{-1}$. 


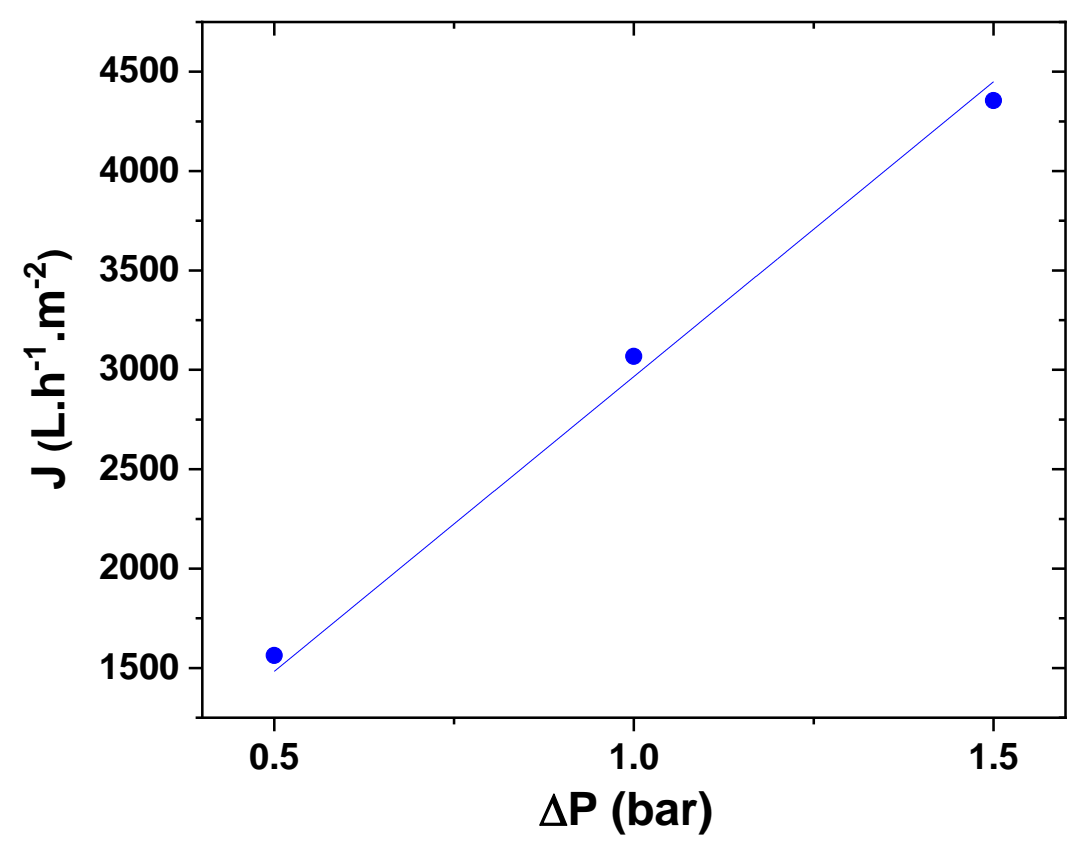

Figure S8: Water flux, $J$, of the hydrophilic PVDF support used in this work. The commercial PVDF support exhibits a water permeability of $2960 \mathrm{~L} \mathrm{~h}^{-1} \mathrm{~m}^{-2}$ bar $^{-1}$.

\begin{tabular}{|c|c|c|c|c|c|}
\hline $\begin{array}{c}\text { Pressure } \\
\text { (Bar) }\end{array}$ & $\begin{array}{c}\text { Sample 1 } \\
\left(\text { L.m }^{-2} \cdot h^{-1}\right)\end{array}$ & $\begin{array}{c}\text { Sample 2 } \\
\left(\text { L.m }^{-2} \cdot \mathbf{h}^{-1}\right)\end{array}$ & $\begin{array}{c}\text { Sample 3 } \\
\left(\text { L.m }^{-2} \cdot h^{-1}\right)\end{array}$ & $\begin{array}{c}\text { Mean Value } \\
\left(\mathbf{L} \cdot \mathbf{m}^{-2} \cdot \mathbf{h}^{-1}\right)\end{array}$ & $\begin{array}{l}\text { SD Value } \\
\left(\mathbf{L} \cdot \mathbf{m}^{-2} \cdot \mathbf{h}^{-1}\right)\end{array}$ \\
\hline 0.5 & 220 & 138 & 97 & 152 & 63 \\
\hline 1.0 & 441 & 280 & 200 & 307 & 123 \\
\hline 1.5 & 690 & 458 & 379 & 509 & 162 \\
\hline
\end{tabular}

Table S1: Permeability test results for three different NIPS-made PS- $b$-P2VP- $b$-PEO/hPS thick film samples measured at pressures between 0 and 1.5 bar. Mean and standard deviation (SD) values of the each permeability result are also given.

\begin{tabular}{|c|c|c|c|c|c|}
\hline $\begin{array}{c}\text { Pressure } \\
\text { (Bar) }\end{array}$ & $\begin{array}{l}\text { Sample 1 } \\
\left(\text { L.m }^{-2} \cdot \mathbf{h}^{-1}\right)\end{array}$ & $\begin{array}{c}\text { Sample 2 } \\
\left(\mathbf{L} \cdot \mathbf{m}^{-2} \cdot \mathbf{h}^{-1}\right)\end{array}$ & $\begin{array}{l}\text { Sample 3 } \\
\left(\mathbf{L} \cdot \mathbf{m}^{-2} \cdot \mathbf{h}^{-1}\right)\end{array}$ & $\begin{array}{c}\text { Mean Value } \\
\left(\mathbf{L} \cdot \mathbf{m}^{-2} \cdot \mathbf{h}^{-1}\right)\end{array}$ & $\begin{array}{l}\text { SD Value } \\
\left(\mathbf{L} \cdot \mathbf{m}^{-2} \cdot \mathbf{h}^{-1}\right)\end{array}$ \\
\hline 0.5 & 282 & 417 & 323 & 341 & 69 \\
\hline 1.0 & 850 & 925 & 692 & 822 & 119 \\
\hline 1.5 & 1482 & 1433 & 1141 & 1352 & 184 \\
\hline
\end{tabular}

Table S2: Permeability test results for three different solvent-annealed (45 min, $\mathrm{CHCl}_{3}$ ) PS- $b$ $\mathrm{P} 2 \mathrm{VP}-b$-PEO/hPS thick film samples measured at pressures between 0 and 1.5 bar. Mean and standard deviation (SD) values of the each permeability result are also given. 


\begin{tabular}{|c|c|c|c|c|c|}
\hline $\begin{array}{c}\text { Pressure } \\
\text { (Bar) }\end{array}$ & $\begin{array}{c}\text { Sample 1 } \\
\left(\text { L.m }{ }^{-2} \cdot h^{-1}\right)\end{array}$ & $\begin{array}{c}\text { Sample } 2 \\
\left(\text { L.m }^{-2} \cdot \mathbf{h}^{-1}\right)\end{array}$ & $\begin{array}{c}\text { Sample } 3 \\
\left(\text { L.m }^{-2} \cdot \mathbf{h}^{-1}\right) \\
\end{array}$ & $\begin{array}{c}\text { Mean Value } \\
\left(\mathbf{L} \cdot \mathbf{m}^{-2} \cdot \mathbf{h}^{-1}\right)\end{array}$ & $\begin{array}{l}\text { SD Value } \\
\left(\mathbf{L} \cdot \mathbf{m}^{-2} \cdot \mathbf{h}^{-1}\right)\end{array}$ \\
\hline 0.5 & 13 & 8 & 25 & 15 & 9 \\
\hline 1.0 & 22 & 22 & 43 & 29 & 12 \\
\hline 1.5 & 42 & 37 & 58 & 46 & 11 \\
\hline
\end{tabular}

Table S3: Permeability test results for three different solvent-annealed (5h, $\left.\mathrm{CHCl}_{3}\right)$ PS- $b$ $\mathrm{P} 2 \mathrm{VP}-b$-PEO/hPS thick film samples measured at pressures between 0 and 1.5 bar. Mean and standard deviation (SD) values of the each permeability result are also given. 